\title{
Settling-depth vs. genotype and size vs. genotype correlations at the Pan I locus in 0-group Atlantic cod Gadus morhua
}

\author{
Svein-Erik Fevolden ${ }^{1, *}$, Jon-Ivar Westgaard ${ }^{1,2}$, Torstein Pedersen ${ }^{1}$, Kim $_{\text {Præbel }}{ }^{1}$ \\ ${ }^{1}$ Department of Arctic and Marine Biology, Faculty of BioSciences, Fisheries and Economics, University of Tromsø, \\ 9037 Tromsø, Norway \\ ${ }^{2}$ Institute of Marine Research, PO Box 6404, 9294 Tromsø, Norway
}

\begin{abstract}
We sampled 0-group juvenile Atlantic cod Gadus morhua L. within fjords and offshore in northern Norway from 1994 to 2008 using different gears for the 3 sampling depths: shore seine $(0-3 \mathrm{~m})$, pelagic trawl (various depths), and bottom trawl (>80 m). Frequencies of alleles at the Pan I locus (4218 fish analysed) showed highly significant differences among samples collected in the different habitats. The Pan $\mathrm{I}^{\mathrm{A}}$ allele showed a mean frequency of $\sim 80 \%$ in the shore seine samples, $12 \%$ in the bottom trawl samples, and between 5 and $57 \%$ in the pelagic samples. These differences are thought to reflect the co-occurrence of different populations of cod in the area with different settling regimes. Shallow-water settlers are thought to represent the stationary Norwegian coastal cod (NCC), the deep-water settlers represent the migratory Arcto-Norwegian cod (ANC), and the non-settled individuals represent a variable mixture of the 2 populations. For designated samples, we analyzed 16 microsatellites (non-neutral and neutral) that supported a genetic divergence between shallow-water and deep-water settlers. Correlations between length and Pan I genotypes within selected samples showed that the Pan $\mathrm{I}^{\mathrm{BB}}$ homozygotes (typical of ANC) were significantly longer than the Pan $\mathrm{I}^{\mathrm{AA}}$ homozygotes (typical of NCC). This could reflect differences in spawning time and growth conditions between ANC and NCC, just as well as one genotype being superior to the others in terms of growth performance. Finally, we argue that the Pan I difference between 0 -group NCC and ANC is not caused by contemporary selection but reflects adaptation on an ecological post-glacial time scale.
\end{abstract}

KEY WORDS: Arcto-Norwegian cod $\cdot$ Norwegian coastal cod $\cdot 0$-group juveniles $\cdot$ Pan I locus · Settling regimes $\cdot$ Population divergence

Resale or republication not permitted without written consent of the publisher

\section{INTRODUCTION}

Following the very first reports on variation in Atlantic cod Gadus morhua L. at the Pan I (pantophysin) locus (Pogson et al. 1995, Fevolden \& Pogson 1995; Pan I is identical to the GM798 clone in those papers), a discussion evolved about the power of this locus as a marker for distinguishing populations due to its non-neutral character. Pantophysin is a membrane protein found in small synaptic transmitter vesicles (Haass et al. 1996), but its function is yet not fully understood, nor are the mechanisms underlying the positive Darwinian selection acting on the gene coding for it (Pogson 2001, Pogson \& Mesa 2004). Various physical and oceanographic features have been suggested to act as selective constraints on the locus, with depth and temperature being frequently mentioned candidates 
(Case et al. 2005, Sarvas \& Fevolden 2005a, Pampoulie et al. 2008). One reason for the initial dispute was that Pan I exhibited profound divergence among populations of Atlantic cod, e.g. over its total distributional area in the North Atlantic (Pogson et al. 1995), where neutral markers like allozymes (Mork et al. 1985) or mtDNA (Árnason 2004) had disclosed only shallow genealogies. Currently there seems to be a general consensus that Pan I is indeed a valid first hand indicator of population divergence in Atlantic cod. The claimed weakness of this locus as being influenced by selection was early on considered its strength, since it can reveal adaptation to local environmental changes earlier than strictly neutral loci (Fevolden \& Pogson 1997, Carvalho \& Hauser 1998). After Atlantic cod in the NE Atlantic and adjacent waters have been studied for variation at an array of microsatellite loci (e.g. Nielsen et al. 2006, Skarstein et al. 2007, Westgaard \& Fevolden 2007, Pampoulie et al. 2011) and single nucleotide polymorphisms (SNPs; e.g. Moen et al. 2008, Nielsen et al. 2009a, Poulsen et al. 2011), the important role of selected markers to reveal adaptive population divergence on ecological time scales seems no longer disputable (see also Waples \& Gagiotti 2006, Helyar et al. 2011, and reviews by Kirk \& Freeland 2011 and Salmenkova 2011). The power of assigning individuals to populations of origin is also strengthened by exploiting loci under selection (Nielsen et al. 2009b).

The most striking divergence at the Pan I locus exhibited over very short distances has been reported from northern Norway (e.g. Fevolden \& Pogson 1997, locus denoted Syp I; Pogson \& Fevolden 2003, Sarvas \& Fevolden 2005a,b). Two major populations of Atlantic cod inhabit coastal waters of northern Norway and the Barents Sea. Norwegian coastal cod $\left(\mathrm{NCC}_{i}\right.$ alternatively called just coastal cod) exhibit very high frequencies of the $P a n \mathrm{I}^{\mathrm{A}}$ allele class $(\sim 80 \%)$, whereas Arcto-Norwegian cod (ANC; identical to Northeast Arctic cod) display similar or even higher frequencies of the Pan $\mathrm{I}^{\mathrm{B}}$ allele $(\sim 90 \%)$. $F_{\mathrm{ST}}$ values of $\sim 0.4$ have been reported between NCC and ANC at this locus (Fevolden \& Pogson 1997, Sarvas \& Fevolden 2005a), meaning that $40 \%$ of the total variance observed at the Pan I is attributable to differences between the 2 populations. Despite these findings and the growing recognition of the advantages of implementing non-neutral loci in studies of genetic population structure, a recent review (Nordeide et al. 2011, p. 269) questioned whether ANC and NCC make up 1 large population or $>1$ noninterbreeding group. The authors claimed that differ- ences between NCC and ANC first and foremost have been reported using markers that are generally agreed to be subject to selection, and thus considered '... less suited to assessing population connectivity'. Such a presumption may be correct if the purpose is to study neutral evolutionary processes (gene flow, genetic drift), but not ecological adaptations on more recent time scales.

The generally recognized NCC inhabit fjords and near-coastal areas and have spawning sites located well inside fjords, but to some extent also in outer coastal areas. Peak spawning normally occurs in March and April (Skreslet \& Danes 1978). NCC are considered relatively stationary, and there seems to be a high fidelity to spawning sites (Godø 1986, Jakobsen 1987, Skjæraasen et al. 2011). The migratory ANC have nursery and feeding grounds in the Barents Sea. After maturation, they perform yearly spawning migrations down to the coast of Norway, where major spawning areas in northern Norway are found in the Lofoten and Vesterålen area and on the inside of relatively shallow near-shore banks off Troms and Finnmark counties (Bergstad et al. 1987). Some of these sites overlap with spawning sites of NCC, allowing for potential intermingling of spawning adults, eggs, and larvae of ANC and NCC. Various mechanisms have been suggested to hamper this intermingling and potential for hybridization between the 2 populations, like differences in peak time of spawning, possible differences in temperature and depth preferences for spawning, and differences in spawning behavior (Nordeide 1998, Nordeide \& Folstad 2000, Sarvas \& Fevolden 2005a; cf. also Grabowski et al. 2011 for similar features for spawning Icelandic cod). Eggs and larvae spawned offshore will drift northeast-ward with the prevailing Norwegian coastal current. By June to July, larvae and small juveniles are found in the southern Barents Sea as well as along the coast of Troms and Finnmark counties. Due to complex near-shore current features (Pedersen et al. 2005), one would expect some larvae to drift into fjords along the coast in the same way that larvae from fjord-spawning cod to some extent can drift out of fjords, again causing pelagic intermingling of the 2 populations before the 0 -group juveniles settle.

The major focus on Pan I variation in Atlantic cod has been on adult harvestable year-classes. To assess whether differences at the Pan I locus could be linked to life history changes, it is crucial to include studies of the young. Here we summarize Pan I data of 0-group juvenile cod sampled in coastal areas of northern Norway in the period 1994 
to 2008. The main objectives were to ascertain whether 0-group juveniles of NCC and ANC are genetically as divergent as their parents, and if the 0-group juveniles of the 2 groups behave differently, intermingling as they may in the pelagic egg or larval stage, but segregating at the time of settling. Using vertebrae numbers to discriminate the 2 populations, NCC juveniles were reported to settle in shallow water, whereas ANC juveniles settled in deeper water (Løken et al. 1994). Therefore, those that settle in shallow water would be expected to be dominated by the most common genotype of Pan I found in adult coastal cod $\left(P a n \mathrm{I}^{\mathrm{AA}}\right)$. The juveniles that settle in deep water would be dominated by the most common Pan I genotype found in adult ANC (Pan $\mathrm{I}^{\mathrm{BB}}$ ). 0-group juveniles sampled pelagically, and thus not yet settled, could represent a mixture of ANC and NCC in areas where they co-occur. To lend support to our hypothesis that differences in Pan I allele frequencies in settled juveniles actually reflect the presence of 2 genetically distinct populations, shallow-water settled juveniles, pelagic non-settled juveniles, and deep-water settlers that were caught at the same location within a few hours' time interval were analyzed for variation at 16 microsatellite loci.

It has been suggested that the Pan I signature of Atlantic cod affects growth. In Norwegian (Fevolden \& Pogson 1995) and Icelandic waters (Jónsdóttir et al. 2002, Imsland \& Jónsdóttir 2003, Jakobsdóttir et al. 2011), the Pan $\mathrm{I}^{\mathrm{AA}}$ homozygotes of post-juvenile cod have been reported to exhibit higher length at age than the Pan $\mathrm{I}^{\mathrm{BB}}$ homozygotes. Jónsdóttir et al. (2008), however, suggested that the genotype that grew fastest around Iceland varied with spawning sites, rendering data on possible growth and Pan I genotype correlations for post-juvenile cod inconclusive. There is a lack of studies relating growth and Pan I genotypes in 0-group cod. A study comparing the growth of different Pan I genotypes within families held under semi-natural conditions showed that 10 wk old larvae of Pan $\mathrm{I}^{\mathrm{AB}}$ heterozygotes grew faster than Pan $\mathrm{I}^{\mathrm{BB}}$ homozygotes (Case et al. 2006). Pan $\mathrm{I}^{\mathrm{AA}}$ homozygotes were not available. In selected samples, we compared the length of 0-group juveniles in the 3 different Pan I genotypes to check for evidence of different growth performance among them.

\section{MATERIALS AND METHODS}

Juvenile 0-group cod were sampled in fjords and offshore waters of northern Norway (Fig. 1) in the period 1994 to 2008. The total 4218 fish analyzed for Pan I were caught in shallow water, 0 to $\sim 3 \mathrm{~m}$, using a shore seine (number of samples: $\mathrm{N}=53$, number of fish analyzed: $n=2743$ ), pelagically (inshore and offshore), at various depths by a pelagic trawl ( $\mathrm{N}=21$, $\mathrm{n}=1128$ ), and at the deep bottom habitat (depth $>80 \mathrm{~m})$ using a bottom trawl $(\mathrm{N}=11, \mathrm{n}=347)$. Details of the different samples are given in Table S1 in the supplement at www.int-res.com/articles/suppl/ m468p267_supp.pdf. All sampling was done in August and September to enable catching newly settled juveniles. Immediately after being caught, the fish were put in $96 \%$ ethanol and stored until being analyzed. A number of samples caught up until 2001 were included in the study of Sarvas \& Fevolden (2005a), who aimed at describing geographic variation of cod in the Northeast Atlantic (their sample number is given in Table S1).

DNA from samples up until 2007 was obtained by a modified salt lysis extraction (Fevolden \& Pogson 1997). DNA from the 2008 samples was isolated using an E-Z96 Tissue DNA Kit (OMEGA Bio-tek) following the manufacturer's instructions. The 2-allele-class (A and B) Pan I locus is in itself a SNP, since a 1-nucleotide substitution decides the presence or absence of a Dra1 restriction site. The locus was analyzed by the polymerase chain reaction (PCR) based method (Fevolden \& Pogson 1997), and only the 2008 samples were analyzed including Pan I on a multiplex of mi-

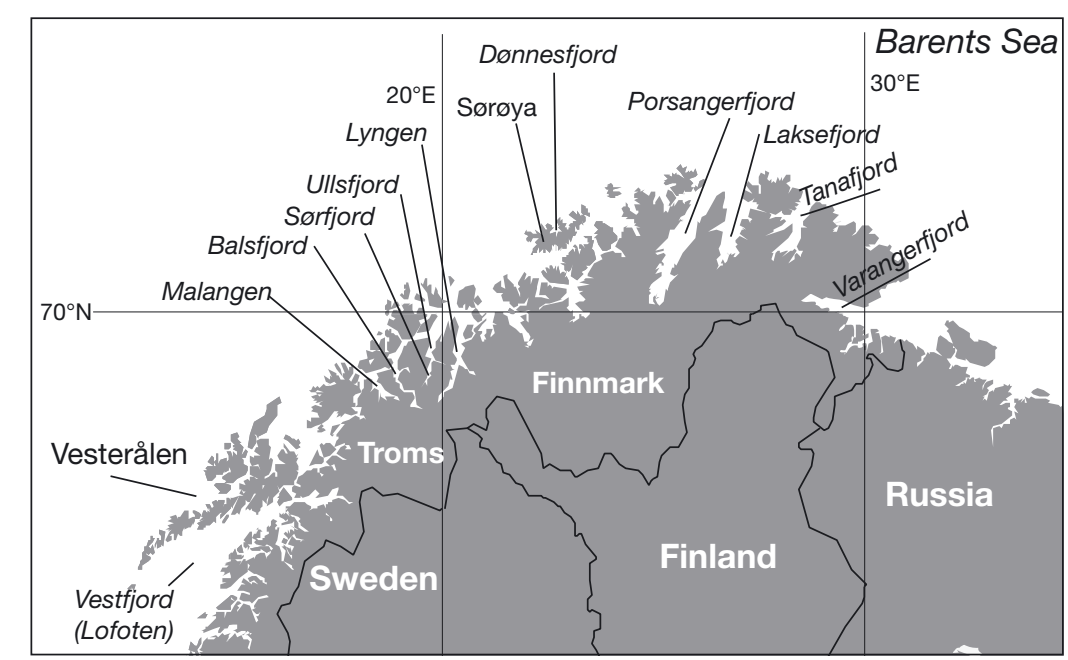

Fig. 1. Gadus morhua. Various fjords in northern Norway where 0-group Atlantic cod were sampled. For detailed locations see Table S1 in the supplement at www.int-res.com/articles/suppl/m468p267_supp.pdf 
crosatellites and genotyped upon fragment analyses on an ABI 3130XL sequencer (Applied Biosystems) according to Stenvik et al. (2006).

In 3 cases when samples were taken within a few hours' interval at different depths for the same locality (cf. Fig. 3 and samples in Table S1 marked by ${ }^{\mathrm{ms}}$ ), the fish ( $\mathrm{n}=521$ ) were also analyzed for 18 microsatellite loci (see Table 2 plus PGM108 and pGMO55). These were organized in 4 multiplex PCRs. PCRs were carried out in a $10 \mu \mathrm{l}$ reaction containing $50 \mathrm{mM} \mathrm{KCl}, 10 \mathrm{mM}$ Tris- $\mathrm{HCl}, 400 \mu \mathrm{M}$ dNTP, $1.5 \mathrm{mM} \mathrm{MgCl}_{2}, 0.1$ to $1.0 \mu \mathrm{M}$ primer, and 0.5 units Taq polymerase. The PCR profile for the multiplex PCR was an initial denaturation step of $94^{\circ} \mathrm{C}$ for $10 \mathrm{~min}$ followed by 25 cycles of $94^{\circ} \mathrm{C}$ for $20 \mathrm{~s}, 56^{\circ} \mathrm{C}$ $\left(51^{\circ} \mathrm{C}\right.$ for multiplex 3$)$ for $30 \mathrm{~s}$, and $72^{\circ} \mathrm{C}$ for $1 \mathrm{~min}$, ending with an elongation step of $72^{\circ} \mathrm{C}$ for $10 \mathrm{~min}$. Electrophoresis of the amplified PCR products was performed using an ABI 3100 automated sequencer (Applied Biosystems). Alleles were scored using Genemapper 3.7 software (Applied Biosystems), using the automated binning function and subsequent manual verification. All microsatellite loci were initially run through the Micro-checker software (Van Oosterhout et al. 2004) for detection of possible null alleles or scoring errors.

For statistical analyses, the samples were grouped into gear (habitat) categories (shore seine: SS, pelagic trawl: PT, and deep bottom trawl: BT). The overall means of allele frequencies in each category were calculated both as arithmetic means of the frequencies in each individual sample of the different categories and from the total number of genotypes in the pooled sample set for each gear category. To examine possible variation in allele frequencies over years, all samples of 0-group cod taken at a specific year and habitat, independent of locality, were summarized, and average allele frequencies for each year were calculated both as arithmetic means over samples as well as from the total number of genotypes sampled for that year. The PT samples and in particular the BT samples were low in numbers compared to the SS samples (mainly due to lower sampling effort using those gear types), and frequencies for a particular year are occasionally only from 1 sample.

$F_{\text {IS }}$ for individual samples (Tables S1 and S2) and pairwise $F_{\mathrm{ST}}$ between samples analyzed for microsatellites (see Table 2) were calculated using Genepop 4.0 (Rousset 2008), following Weir \& Cockerham (1984). $F_{\mathrm{IT}}$ and $F_{\mathrm{ST}}$ for pooled samples within each sampling gear (Pan I data; Table 1) and their corresponding $\mathrm{p}$ values were calculated using the analysis of molecular variance (AMOVA) option in the soft- ware Arlequin 3.5 (Excoffier \& Lischer 2010). Corresponding SE were estimated using the software FSTAT 2.9.3 (Goudet 2001). To visualize relationships among the 7 samples analyzed for microsatellites (Fig. 3), a multi-dimensional scaling (MDS) plot was produced using XLSTAT (Addinsoft). The MDS plot was based on Nei's $D_{\mathrm{A}}$ genetic distance (Nei et al. 1983). To detect possible outlier loci among the microsatellites, we used the Bayesian likelihood method implemented via reversible jump Markov Chain Monte Carlo in BAYESCAN (Foll \& Gaggiotti 2008).

The 3 Varangerfjord samples of Fig. 3 were used in a mixed stock analysis (MSA) with GeneClass 2.0 software (Piry et al. 2004). The SS and BT juveniles were used as reference samples, with the PT juveniles classified as unknown. The distribution of individuals in the pelagic sample representing each of the 2 reference groups was estimated from 2 non-neutral microsatellites (GMO34 and GMO132; see below) plus Pan I. A linear regression method based on the proportion of Pan $\mathrm{I}^{\mathrm{B}}$ alleles in a sample (G. Dahle unpublished) was used to estimate the proportion of NCC and ANC in all 3 pelagic samples of Fig. 3.

Length in mm was measured for juveniles in 3 designated samples, either as standard length (excluding the caudal fin) or total length. The length was compared between the different Pan I genotypes. Some of the length-frequency distributions differed significantly from normality when tested with a Lilliefors test. Thus, significance of differences between length distributions of the different Pan I genotypes was tested by the nonparametric MannWhitney 2-sample test.

\section{RESULTS}

\section{Pan I allele frequencies and depth}

The frequency of the 2 Pan I alleles varied drastically with sampling gear and thus habitat (Fig. 2),

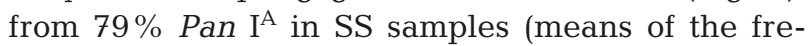

Table 1. Gadus morhua. Wright's $F_{\mathrm{IT}}$ and $F_{\mathrm{ST}}$ values $\pm \mathrm{SE}$ for the Pan I locus for all samples caught with each of the 3 sampling gears (shore seine: $\mathrm{SS}_{\text {; }}$ pelagic trawl: $\mathrm{PT}_{i}$ bottom trawl: BT). ns: not significant

\begin{tabular}{|ccccc|}
\hline Gear & $F_{\text {IT }}$ & $p$ & $F_{\text {ST }}$ & $p$ \\
\hline SS & $0.177 \pm 0.034$ & $<0.001$ & $0.062 \pm 0.014$ & $<0.001$ \\
PT & $0.286 \pm 0.058$ & $<0.001$ & $0.118 \pm 0.038$ & $<0.001$ \\
BT & $0.131 \pm 0.091$ & $<0.05$ & $0.020 \pm 0.016$ & ns \\
\hline
\end{tabular}




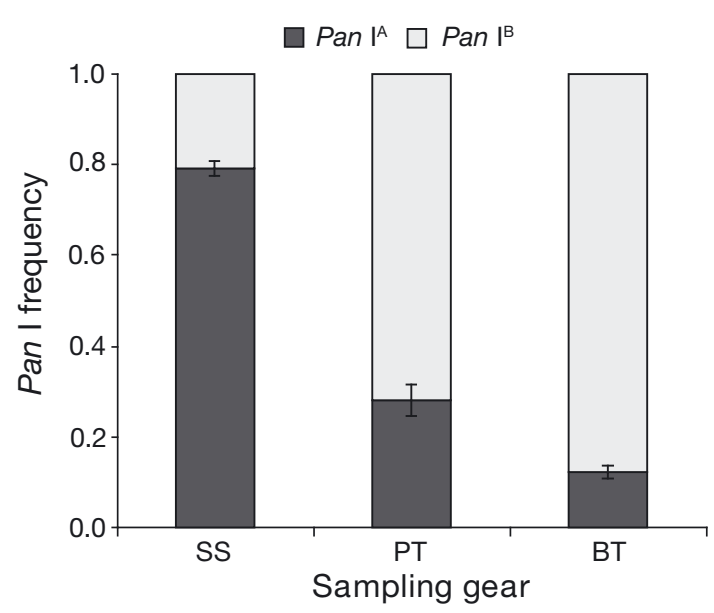

Fig. 2. Gadus morhua. Frequencies of the 2 Pan I alleles of 0-group Atlantic cod of all shore seine (SS), pelagic trawl

$(\mathrm{PT})$, and bottom trawl (BT) samples. Means \pm SEM

quencies in each sample; $80 \%$ when calculated from the pooled number of genotypes) to only $12 \% \operatorname{Pan~} \mathrm{I}^{\mathrm{A}}$ (both estimates) for 0-group juveniles caught by BT. The more intermediate mean frequencies for juveniles caught pelagically, $28 \%$ (29\% estimated from the number of pooled genotypes), exhibited the largest among-sample variation, with $\operatorname{Pan} \mathrm{I}^{\mathrm{A}}$ frequencies ranging from 5 to $57 \%$ (Table S1). No correlation between sampling depth and $\operatorname{Pan} \mathrm{I}^{\mathrm{A}}$ frequencies was found for the pelagic samples $\left(R^{2}=0.031, p=0.445\right)$. We also found no differences in mean frequencies of the Pan $\mathrm{I}^{\mathrm{A}}$ allele between pelagic juveniles sampled offshore $(0.28 \pm 0.17)$ and inshore $(0.29 \pm 0.16)$. The distribution of genotypes relative to Hardy-Weinberg expectations showed that both the PT samples (6 out of $21 ; 28.6 \%$ ) and the SS samples (8 out of $53 ; 15.1 \%$ ) displayed significant deficits of heterozygotes, indicative of having sampled populations of different genetic origin (Wahlund effect). One of the 11 BT samples $(9.1 \%)$ deviated significantly from HardyWeinberg expectations, showing a deficit of heterozygotes. None of the samples displayed significant excesses of heterozygotes. Both $F_{\mathrm{ST}}$ and $F_{\mathrm{IT}}$ values within habitats were larger (and highly significant) for the PT samples than for SS and BT samples (Table 1).

Samples that were taken within few hours' time intervals from different habitats in 3 different fjords were compared (Fig. 3). In Varangerfjord, we observed Pan I allele frequencies very similar to the total sample set (Fig. 2). In Porsangerfjord and Laksefjord, only SS and PT samples were available. The Pan $\mathrm{I}^{\mathrm{A}}$ allele frequency in the PT samples differed between the 2 fjords, but in both, a significantly

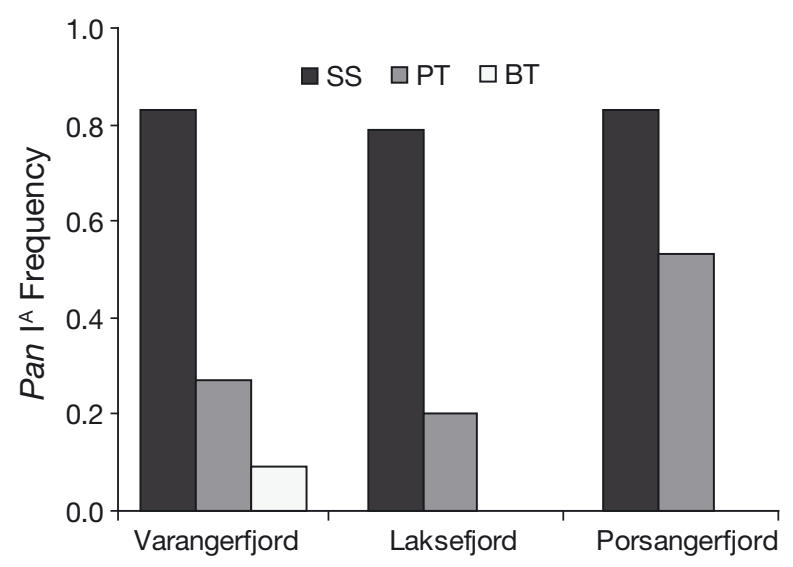

Fig. 3. Gadus morhua. Pan $\mathrm{I}^{\mathrm{A}}$ allele frequency of 0-group Atlantic cod sampled within a few hours' time interval with different gear (see Fig. 2) in 3 fjords. Varangerfjord: sampled on 31 August and 1 September 1996, Laksefjord: 2 September 1996, Porsanger: 4 October 2000

lower Pan $\mathrm{I}^{\mathrm{A}}$ allele frequency was observed in the PT sample as compared to the SS sample (Fig. 3; pairwise $F_{\mathrm{ST}}, \mathrm{p}<0.001$ ).

The 7 sample sets of Fig. 3 were initially analyzed for variation at 18 microsatellite loci. Microchecker indicated that the locus GMA108 was severely under the influence of null alleles, and pGMO55 showed large heterozygote excess, indicative of scoring errors. Thus, these 2 loci were subsequently excluded from further analysis. Basic genetic data for the remaining 16 microsatellites are given in Table S2. Estimates of pairwise $F_{\mathrm{ST}}$ over all loci (Table 2; total $\mathrm{ms}$ ) were in general low, but highest when comparing shore and deep bottom samples of Varangerfjord $\left(F_{\mathrm{ST}}=0.0122, \mathrm{p}<0.001\right)$. Significant differences between shore and pelagic samples were found in Varangerfjord and Laksefjord, but not in Porsangerfjord (Table 2). Large contributors to the significant differences were loci GMO34 and GMO132, which both showed posterior probabilities $>0.99$ in the Bayesian selection test, thus being considered nonneutral. When excluding those loci and estimating $F_{\text {ST }}$ values based on the neutral loci only, significant differences were still seen between bottom and SS samples in Varangerfjord $\left(F_{\mathrm{ST}}=0.003, \mathrm{p}<0.05\right)$, and between pelagic and SS samples in Laksefjord $\left(F_{\mathrm{ST}}=\right.$ $0.003, \mathrm{p}<0.001) . F_{\mathrm{ST}}$ values from the Pan I locus were, not surprisingly, significant for all pairwise comparisons of Table 2.

The MDS plot of microsatellite data (Fig. 4) shows that the SS samples of Fig. 3 are clustered in 1 dimension, whereas the pelagic trawl samples are grouped across dimensions. The $1 \mathrm{BT}$ sample appears as an outgroup. Mixed stock analysis of the 3 Varanger- 
Table 2. Gadus morhua. Pairwise $F_{\mathrm{ST}}$ comparison over 16 microsatellite loci plus Pan I for samples from 3 fjords (Porsanger: $\mathrm{P}$, Lakse: L, and Varanger: V) taken with shore seine (SS), pelagic trawl (PT), or bottom trawl (BT). Dates of sampling are as in Fig. 3. $\mathrm{P}$ values are from exact tests. Significant $\mathrm{p}$-values are in bold. Total $\mathrm{ms}=$ all 16 microsatellites. Neutral $\mathrm{ms}=$ exclusion of non-neutral microsatellites (GMO34 and GMO132). SE in ( ) for $F_{\mathrm{ST}}$ estimates across loci. Superscripts 1 to 4 : Multiplex 1 to 4

\begin{tabular}{|c|c|c|c|c|c|c|c|c|c|c|}
\hline \multirow[t]{2}{*}{ Locus } & \multicolumn{2}{|c|}{ PSS - PPT } & \multicolumn{2}{|c|}{ LSS - LPT } & \multicolumn{2}{|c|}{ VSS - VPT } & \multicolumn{2}{|c|}{ VSS - VBT } & \multicolumn{2}{|c|}{ VPT - VBT } \\
\hline & $F_{\mathrm{ST}}$ & $\mathrm{p}$ & $F_{\mathrm{ST}}$ & $\mathrm{p}$ & $F_{\mathrm{ST}}$ & $\mathrm{p}$ & $F_{\mathrm{ST}}$ & $\mathrm{p}$ & $F_{\mathrm{ST}}$ & $\mathrm{p}$ \\
\hline $\mathrm{GMO}^{2}$ & -0.0008 & 0.265 & -0.0010 & 0.468 & 0.0060 & 0.038 & 0.0051 & 0.594 & 0.0333 & 0.001 \\
\hline $\mathrm{GMO}^{2}$ & 0.0084 & 0.849 & 0.0013 & 0.701 & 0.0019 & 0.344 & -0.0069 & 0.910 & -0.0160 & 0.363 \\
\hline GMO8 $^{1}$ & & & 0.0073 & 0.001 & 0.0020 & 0.029 & 0.0015 & 0.283 & -0.0028 & 0.921 \\
\hline GMO19 $^{1}$ & -0.0013 & 0.539 & -0.0013 & 0.645 & -0.0021 & 0.854 & 0.0042 & 0.087 & 0.0016 & 0.169 \\
\hline GMO34 $^{2}$ & -0.0054 & 0.118 & 0.0707 & $<0.001$ & 0.0499 & $<0.001$ & 0.1020 & $<0.001$ & 0.0185 & 0.101 \\
\hline $\mathrm{GMO} 7^{1}$ & -0.0066 & 0.980 & 0.0044 & 0.016 & -0.0025 & 0.666 & -0.0026 & 0.110 & -0.0051 & 0.766 \\
\hline $\mathrm{GMO} 132^{2}$ & -0.0068 & 0.944 & 0.0379 & 0.003 & 0.0508 & $<0.001$ & 0.0631 & $<0.001$ & -0.0044 & 0.795 \\
\hline $\mathrm{PGMO}^{4} 2^{4}$ & 0.0026 & 0.320 & 0.0018 & 0.188 & 0.0052 & 0.195 & 0.0097 & 0.104 & -0.0071 & 0.553 \\
\hline GMA107 & 0.0003 & 0.621 & 0.0038 & 0.042 & 0.0010 & 0.148 & 0.0030 & 0.084 & 0.0036 & 0.008 \\
\hline $\mathrm{TCH}^{4}$ & -0.0001 & 0.500 & 0.0043 & 0.983 & -0.0011 & 0.865 & 0.0107 & 0.144 & 0.0073 & 0.237 \\
\hline $\mathrm{TCH}_{11}{ }^{1}$ & -0.0015 & 0.661 & 0.0019 & 0.064 & -0.0020 & 0.826 & -0.0010 & 0.355 & 0.0023 & 0.248 \\
\hline $\mathrm{TCH}_{13}{ }^{2}$ & 0.0085 & 0.132 & 0.0063 & 0.009 & -0.0008 & 0.231 & 0.0044 & 0.017 & -0.0090 & 0.697 \\
\hline $\mathrm{TCH}_{14}{ }^{3}$ & -0.0013 & 0.285 & 0.0042 & 0.127 & 0.0007 & 0.557 & 0.0097 & 0.050 & 0.0016 & 0.294 \\
\hline TCH16 ${ }^{3}$ & 0.0274 & 0.097 & 0.0167 & 0.123 & -0.0035 & 0.622 & -0.0050 & 1.000 & -0.0011 & 1.000 \\
\hline TCH19 3 & -0.0085 & 0.574 & 0.0029 & 0.646 & 0.0100 & 0.121 & -0.0091 & 0.571 & 0.0031 & 0.619 \\
\hline $\mathrm{TCH} 22^{3}$ & 0.0009 & 0.551 & 0.0169 & 0.051 & -0.0017 & 0.909 & -0.0015 & 0.365 & -0.0028 & 0.505 \\
\hline Total ms & $\begin{array}{c}-0.0010 \\
(0.001)\end{array}$ & 0.459 & $\begin{array}{c}0.0082 \\
(0.004)\end{array}$ & $<0.001$ & $\begin{array}{c}0.0056 \\
(0.004)\end{array}$ & 0.001 & $\begin{array}{c}0.0122 \\
(0.006)\end{array}$ & $<0.001$ & $\begin{array}{c}0.0032 \\
(0.003)\end{array}$ & 0.032 \\
\hline Neutral ms & $\begin{array}{c}-0.0004 \\
(0.001)\end{array}$ & 0.559 & $\begin{array}{c}0.0030 \\
(0.001)\end{array}$ & $<0.001$ & $\begin{array}{c}0.0005 \\
(0.001)\end{array}$ & 0.305 & $\begin{array}{c}0.0029 \\
(0.001)\end{array}$ & 0.023 & $\begin{array}{c}0.0033 \\
(0.003)\end{array}$ & 0.059 \\
\hline Pan I & 0.3798 & $<0.001$ & 0.2085 & $<0.001$ & 0.4615 & $<0.001$ & 0.7071 & $<0.001$ & 0.1110 & $<0.001$ \\
\hline
\end{tabular}

fjord samples of Fig. 3, using Pan I, GMO34, and GMO132 as markers, and shallow settlers (alleged NCC) and bottom settlers (alleged ANC) as reference groups, gives a proportion of $28 \%$ NCC and $72 \%$ ANC in the pelagic trawl sample. Using the method based on Pan $\mathrm{I}^{\mathrm{B}}$ frequencies in a sample assumed to be a mixture between NCC and ANC, gives a proportion of NCC in the pelagic sample in Varangerfjord of $24 \%$, Laksefjord $15 \%$, and Porsangerfjord $54 \%$ (Table 3).

\section{Pan I allele frequencies over years}

Frequencies of Pan I alleles in 0group juveniles settling in shallow water, irrespective of sampling location, were compared over the $14 \mathrm{yr}$ time span of the study. SS samples were not available from 2002 to 2006 due to a temporary stop in sampling activities. As evident from Fig. 5, SS 0-group juveniles that settled in shallow water in northern Norway displayed high Pan I ${ }^{\mathrm{A}}$ stability over the total sampling period. The apparent

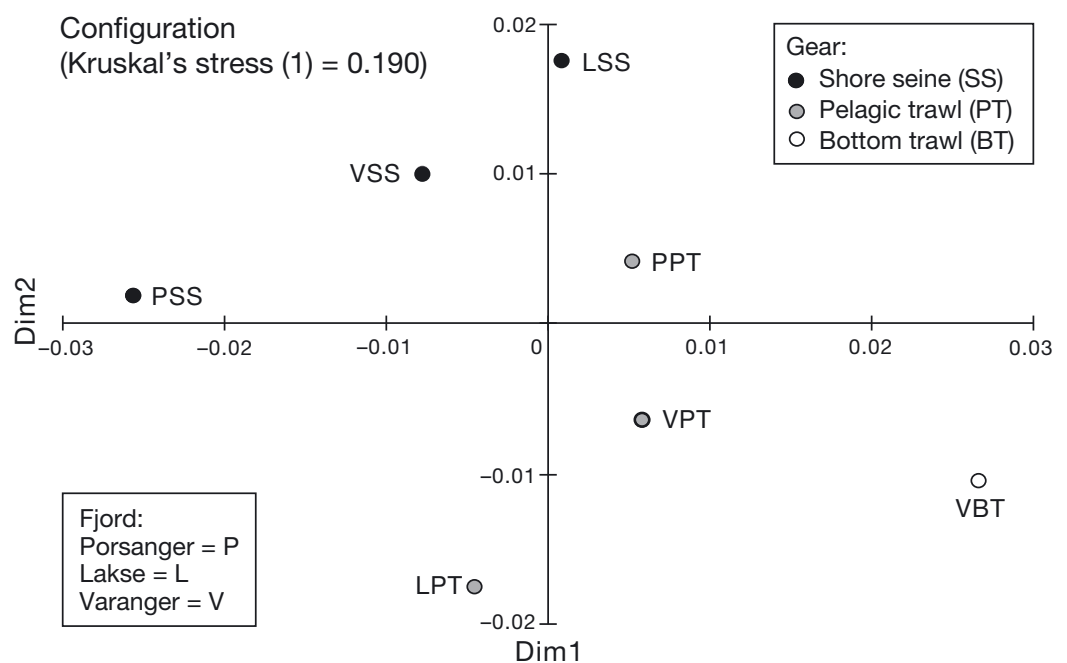

Fig. 4. Gadus morhua. Multidimensional scaling (MDS) plot of the 7 samples of Fig. 3 based on the 16 microsatellites of Table 2

lower $\operatorname{Pan} \mathrm{I}^{\mathrm{A}}$ frequencies in 2001 and 2007 are associated with few samples available (1 and 3 ) in those years. Frequencies of the Pan $\mathrm{I}^{\mathrm{A}}$ allele of Fig. 5 are means over years. Frequencies calculated by summarizing the different genotypes for each year deviate from the former in 8 of $9 \mathrm{yr}$ by an average of only $1 \%$. In the 3 samples from 2007, the largest (in num- 
ber of fish) showed an unusual low frequency of the Pan $\mathrm{I}^{\mathrm{A}}$ allele (0.62), causing a drop in estimates of Pan $\mathrm{I}^{\mathrm{A}}$ allele frequencies based on the total number of genotypes by $5 \%$. This particular sample was taken on full high tide, allowing for possible drift of non-settled pelagic larvae into the shore seine. The sample displays a significant deficit of heterozygotes (63 observed versus 81 expected: $p$ $<0.05$ ) indicating a Wahlund effect and a mixture of populations. One additional shore seine haul was taken a few hours later at the same location, and the $\operatorname{Pan} \mathrm{I}^{\mathrm{A}}$ allele frequency within this sample (0.78)

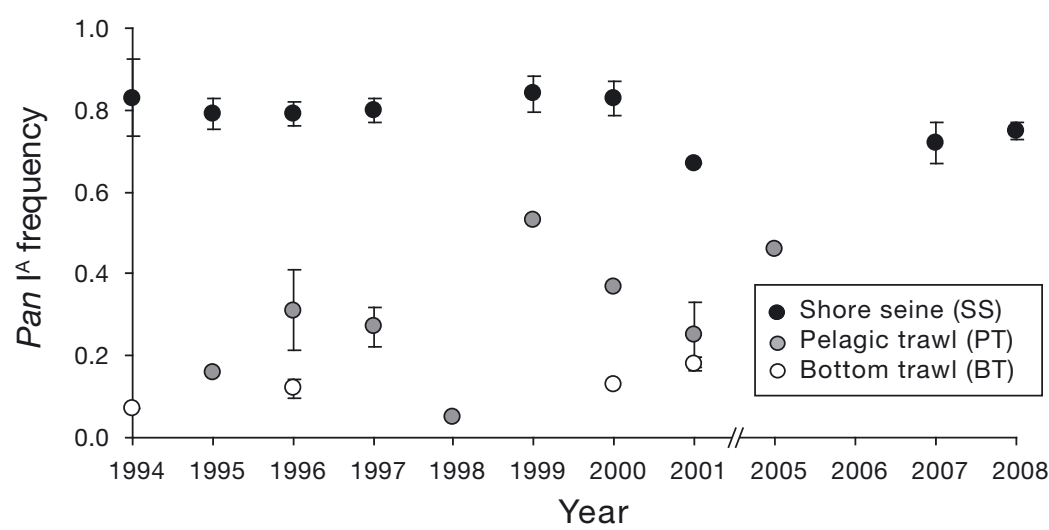

Fig. 5. Gadus morhua. Pan $\mathrm{I}^{\mathrm{A}}$ allele frequency in 0-group cod of samples taken the same year with 3 different sampling gears. Means \pm SEM

was close to the total average for SS sam-

ples (cf. Fig. 2), albeit still displaying a significant (p $<0.05)$ deficit of heterozygotes. The Pan $\mathrm{I}^{\mathrm{A}}$ frequencies in samples of juveniles caught pelagically varied considerably among years, whereas they were always low in deep-water bottom samples (Fig. 5).

\section{Pan I genotypes and length frequencies}

In 3 sample sets of 0-group juveniles (Fig. 6), length was measured for each analyzed fish and related to the 3 possible genotypes, the 2 homozygotes Pan $\mathrm{I}^{\mathrm{AA}}$ and $\operatorname{Pan} \mathrm{I}^{\mathrm{BB}}$, and the heterozygote Pan $\mathrm{I}^{\mathrm{AB}}$. In the pelagic sample (Lyngsfjord), where all 3 genotypes were represented in fairly good numbers, there was a clear result of Pan $\mathrm{I}^{\mathrm{BB}}$ representing the largest individuals, Pan $\mathrm{I}^{\mathrm{AA}}$ the smallest, and the heterozygotes intermediate of the 2 homozygotes (Fig. 6a). Pairwise comparisons of length in all 3 genotypes came out highly significant (Table 4). This sample exhibited a highly significant deficit of heterozygotes (29 versus $48, \mathrm{p}<0.001$ ), clearly demonstrating the mixed population feature of pelagic juveniles. The SS sample

Table 3. Gadus morhua. Percent proportion of Norwegian coastal cod (NCC) and Arcto-Norwegian cod (ANC) in the pelagic samples from Varangerfjord, Laksefjord, and Porsangerfjord (see Fig. 3), estimated from mixed stock analysis (MSA; Varangerfjord only) using the markers GMO34, GMO132, and Pan I, or from the Pan $\mathrm{I}^{\mathrm{B}}$ method (cf. 'Materials and methods')

\begin{tabular}{|c|c|c|c|c|}
\hline \multirow[t]{2}{*}{ Fjord } & \multicolumn{2}{|c|}{$-\mathrm{MSA}-$} & \multicolumn{2}{|c|}{ Pan $\mathrm{I}^{\mathrm{B}}$ method } \\
\hline & $\mathrm{NCC}$ & ANC & $\mathrm{NCC}$ & ANC \\
\hline Varanger & 28.1 & 71.9 & 24 & 76 \\
\hline Lakse & - & - & 15 & 85 \\
\hline Porsanger & - & - & 54 & 46 \\
\hline
\end{tabular}

from Dønnesfjord showed the same pattern as the pelagic sample (Fig. 6b). Pan $\mathrm{I}^{\mathrm{AA}}$ homozygotes were significantly smaller than both the Pan $\mathrm{I}^{\mathrm{BB}}$ homozygotes and the Pan $\mathrm{I}^{\mathrm{AB}}$ heterozygotes, whereas the Pan $\mathrm{I}^{\mathrm{BB}}$ homozygotes were only insignificantly larger than the heterozygotes (Table 4). The mere 3 Pan $\mathrm{I}^{\mathrm{BB}}$ homozygotes from Malangen made a comparison between those and the other genotypes there inappropriate, but again Pan $\mathrm{I}^{\mathrm{AA}}$ homozygotes were significantly $(\mathrm{p}<0.05)$ smaller than the heterozygotes (Fig. 6c).

\section{DISCUSSION}

\section{Vertical divergence}

The present data clearly show that Atlantic cod 0-group juveniles settling in shallow waters in northern Norway are dominated by the Pan $\mathrm{I}^{\mathrm{A}}$ allele class. The samples of juveniles collected by bottom trawl (inshore and offshore) had very low frequencies of that allele and thus correspondingly high frequencies of the Pan $\mathrm{I}^{\mathrm{B}}$ allele. Yet non-settled juveniles caught by the pelagic trawl displayed great variability in frequencies of the 2 alleles, which we take as evidence for variable proportions of 2 populations, ANC and NCC being present pelagically before they segregate to settle. The lack of correlation between Pan I allele frequencies and depth within the pelagic habitat, together with lack of differences between Pan I allele frequencies inside fjords and off the coast, signify an apparent arbitrary distribution of 0-group individuals before they are ready to settle. The lowest $\operatorname{Pan} \mathrm{I}^{\mathrm{A}}$ frequency (0.05) and thus the highest Pan $\mathrm{I}^{\mathrm{B}}$ frequency was in fact observed in a sample from the innermost part of Porsangerfjord, clearly 

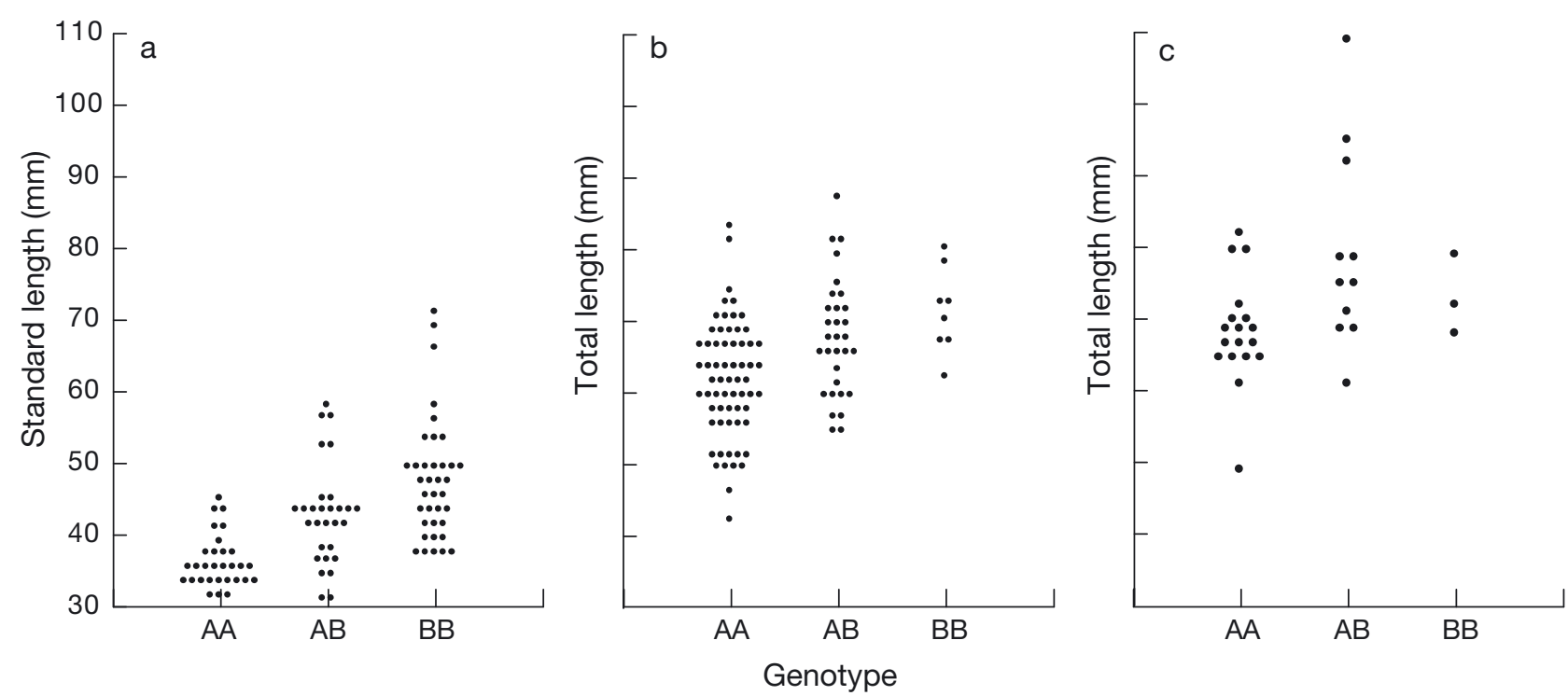

Fig. 6. Gadus morhua. Length plot of the 3 different Pan I genotypes, Pan $\mathrm{I}^{\mathrm{AA}}$, Pan $\mathrm{I}^{\mathrm{AB}}$, and Pan $\mathrm{I}^{\mathrm{BB}}$, in 3 samples of 0 -group Atlantic cod. (a) Pelagic trawl from Lyngsfjord 3 September 2005, (b) shore-seine sample from Dønnesfjord 17 September 2008, (c) shore-seine sample from Malangen (Aursfjord) 16 September 2008

Table 4. Gadus morhua. Mann-Whitney tests for equality of length-frequency distributions of different Pan I genotypes (AA, $\mathrm{AB}, \mathrm{BB}$ ) in 0-group Atlantic cod from 3 different fjords (same as in Fig. 4). Lilliefors tests for normality of length-frequency distributions are given; $\mathrm{p}<0.05$ indicates non-normality

\begin{tabular}{|c|c|c|c|c|c|c|c|c|c|}
\hline \multirow[t]{2}{*}{ Fjord } & \multicolumn{2}{|c|}{$-\mathrm{AA}$ vs $\mathrm{AB}-$} & \multicolumn{2}{|c|}{$-\mathrm{AB}$ vs $\mathrm{BB}-$} & \multicolumn{2}{|c|}{ - $\mathrm{AA}$ vs $\mathrm{BB}-$} & \multicolumn{3}{|c|}{ — Normality Lilliefors } \\
\hline & $U$ & $\mathrm{p}$ & $U$ & $\mathrm{p}$ & $U$ & $\mathrm{p}$ & $\mathrm{AA}$ & $\mathrm{AB}$ & BB \\
\hline Lyngs & 176.5 & $<0.001$ & 350 & 0.016 & 76.5 & $<0.001$ & 0.009 & 0.011 & 0.005 \\
\hline Dønnes & 615.5 & 0.003 & 85 & 0.174 & 82.5 & 0.002 & 0.734 & 0.504 & 0.491 \\
\hline Malangen & 46.0 & 0.017 & 13.5 & 0.173 & 20.0 & 0.585 & 0.016 & 0.173 & 0.038 \\
\hline
\end{tabular}

illustrating that ANC juveniles may drift into fjords by means of local current patterns. The relatively frequent significant deficits of heterozygotes in the PT samples $(28.6 \%)$, together with high and significant $F_{\text {ST }}$ and $F_{\text {IT }}$ values within the pelagic habitat, support the assumption of a varying degree of intermingling between 2 populations in that habitat. Also among the $53 \mathrm{SS}$ samples, $15.1 \%$ exhibited significant deficits of heterozygotes and a high $F_{\mathrm{ST}}$ estimate (Table 1), providing evidence that there is not necessarily an absolute segregation of the 2 populations even after settling. Some ANC juveniles may settle in shallow water before they migrate towards deeper water, or they have not actually settled at the time of being caught in the shore seine.

The sharp settling depth stratification shown herein of Pan I allele frequencies is extraordinary and to our knowledge is unparalleled elsewhere for adult cod or for juveniles. We believe a different settling strategy is 1 of probably many means to maintain the segregation of 2 populations despite the fact that they partly overlap in distribution during the spawning season. The peculiarity of NCC and ANC to maintain separate life history strategies, stationary versus migratory, one would assume has a strong genetic component. Thus, the sharp divergence at the Pan I locus demonstrated herein between 0-group juveniles settled at different depths would not point to contemporary post-settlement selection acting on cohorts from a common gene pool. On the contrary, we believe the 2 discriminated groups of 0-group juveniles are offspring of parental cod with similar divergent Pan I allele frequencies (many examples of which are given by Fevolden \& Pogson 1997, Sarvas \& Fevolden 2005a,b, Westgaard \& Fevolden 2007).

The microsatellite data provide support for the deep bottom-settling juveniles in Varangerfjord being genetically distinguishable from those having settled in shallow water. The pelagic samples of juveniles from Varangerfjord and Laksefjord were also significantly divergent from the shallow-water set- 
tlers in the respective fjords, apparently due to the high proportion of ANC juveniles in the pelagic samples (76 and 85\%, Table 3). The Porsangerfjord pelagic sample with a higher frequency of the Pan $\mathrm{I}^{\mathrm{A}}$ allele (Fig. 3), and thus lower proportion of ANC juveniles $(46 \%)$, was not distinguishable from SS juveniles by means of microsatellites. The MDS plot of microsatellites shows a reasonable grouping of the SS samples in 1 dimension, whereas the pelagic samples are grouped across dimensions, presumably due to their variable proportion of NCC and ANC in them.

The fact that 2 of the microsatellite loci that contribute to the significance in pairwise habitat comparisons were considered non-neutral, in accordance with previous studies (Nielsen et al. 2006, Skarstein et al. 2007, Westgaard \& Fevolden 2007), is in itself no disqualification of their capacity to reveal population divergence. Rather, the microsatellite data, in line with Pan I, could be suggestive of a relatively recent (post-glacial) diversifying selection having acted on non-neutral loci, whereas the time lag may be insufficiently long to affect neutral loci (cf. Pogson \& Fevolden 2003). Notwithstanding, in the present scenario, even when excluding the non-neutral microsatellites, significant differences were found between bottom settlers and shore settlers in Varangerfjord and between shore settlers and non-settled individuals in Laksefjord. Thus, evidence for NCC and ANC being genetically distinguishable is provided both from non-neutral and neutral loci.

\section{Temporal stability}

The relative temporal stability in Pan I allele frequencies of settled cod juveniles in northern Norway, in both shallow and deep water (Fig. 5), runs counter to reports of adult cod, both in central Norway (Trondheimsfjorden; Karlsson \& Mork 2003) and from fjords in northern Norway, e.g. Balsfjord, Ullsfjord, or Varangerfjord (Sarvas \& Fevolden 2005a,b). Whereas in Trondheimsfjorden, Pan I heterogeneity across years and significant excesses of heterozygotes were ascribed to natural selection (Karlsson \& Mork 2003), inter-annual variation among post-juvenile cod in fjords in northern Norway is more plausibly explained by various degrees of intermingling between ANC and NCC. During the spawning season, ANC 'accidentally' penetrate fjords for feeding purposes, whereas there seem to be more or less permanent resident cod in outer fjord and coastal waters, reachable by NCC, with an ANC
Pan I signature (Westgaard \& Fevolden 2007). Thus, bottom trawl catches of adult cod taken in fjords both in late winter or early spring and in the fall are apt to contain a variable fraction of ANC, causing an apparent spatial and temporal Pan I heterogeneity.

The temporally more homogeneous Pan I allele frequencies exhibited by newly settled 0-group juveniles reflects that shallow settling is primarily an adaptation of cod of the NCC type and deep water settling a characteristic of ANC. Slight inter-annual Pan I divergence was also observed for the shallowwater settlers (Fig. 5), again likely due to mechanical mixing with ANC juveniles. One example given in the Results shows that the shore seine does not necessarily exclusively catch juveniles that have settled, not precluding the general picture of a significant genetic divergence between shallow- and deepwater settlers.

\section{Genotype-length correlations}

In post-juvenile cod, Pan $\mathrm{I}^{\mathrm{AA}}$ homozygotes were reported to exhibit the fastest growth (length-at-age) both among NCC and among the offshore alleged ANC, where this genotype was rare (Fevolden \& Pogson 1995). Pan $\mathrm{I}^{\mathrm{AB}}$ heterozygotes were intermediate in length of the 2 homozygotes. Similar features were recently reported from Icelandic waters (Jakobsdóttir et al. 2011), although growth-genotype relations there have previously been reported to vary among spawning sites (Jónsdóttir et al. 2008). Reports on individual length in NCC and ANC populations, classified by otolith typing, showed no difference in growth between the 2 populations (Berg \& Albert 2003). It was claimed, however, that since NCC mature at a younger age than ANC, growth of NCC slows down relative to ANC after maturation.

The present data showing that 0-group juveniles of the commonest coastal cod genotype Pan IAA $^{\mathrm{AA}}$ were significantly smaller on average in early fall than the Pan $\mathrm{I}^{\mathrm{BB}}$ genotypes, does not inevitably signify slower growth in coastal cod juveniles. Length-at-age is in itself a crude measure of growth, and due to the long spawning season for cod in general, the age of the juvenile fish studied herein could vary by weeks. The spawning period of coastal cod originating from different fjords has also been shown to vary (Otterå et al. 2006). Thus, the larger average length of the present Pan $\mathrm{I}^{\mathrm{BB}}$ juveniles could mean that they are older on average than the coastal cod Pan $\mathrm{I}^{\mathrm{AA}}$ juveniles. They could also have been spawned from larger ANC females, which has been suggested to influence 
larval size (Trippel et al. 1997), and they could have experienced different growth conditions, of which temperature is important for larval cod (Otterlei et al. 1999, Vikebø et al. 2005). Conversely, the mere presence of compelling length-genotype correlations strengthens the evidence that 0-group juveniles of NCC and ANC intermingle during their pelagic phase and are profoundly divergent at the Pan I locus even from the earliest life stages. A genetic component to growth performance cannot be dismissed, and the apparent intermediate length of the Pan $\mathrm{I}^{\mathrm{AB}}$ heterozygote as compared to both homozygotes (Fig. 6a,b) could theoretically even be interpreted as an additive genetic effect. A closer look at the length distribution, however, shows that the heterozygotes are spread over the entire length span and could belong to either of the 2 populations.

\section{Pan I - validity and selective constraints}

An array of new molecular markers is now available and is being used for studies of population structuring in a variety of organisms, including Atlantic cod. Chips for SNPs are about to become commercially available, and thousands of markers can be used to establish population divergence. Many of these will be proven non-neutral, and some may come up with differences between the 2 major Norwegian stocks of cod that can rival the Pan I locus (cf. Moen et al. 2008). This will not preclude the important role that the Pan I locus, itself a SNP, has played since it was first identified as a marker with particularly high potential to discriminate populations of cod (Pogson et al. 1995). The great challenge regarding Pan I is that the mechanisms underlying its selective character are still unresolved. The recognition that NCC and ANC in Norwegian waters partly overlap in distribution but are still genetically strictly divergent at the Pan I locus provides a unique system for a deeper insight into which selective constraints cause this divergence. The coexistence of migratory and stationary stocks of Atlantic cod has been reported from different regions of the North Atlantic (e.g. Robichaud \& Rose 2004, Jakobsdóttir et al. 2011), but nowhere so well defined and with such abrupt differences at the Pan I locus as between ANC and NCC.

Depth correlates with Pan I allele frequencies in adult cod (Case et al. 2005, Sarvas \& Fevolden 2005a, Pampoulie et al. 2008). With depth, one could assume that temperature plays an adaptive role, but the ambient temperature in the regions inhabited by
NCC and ANC varies both in time and space. Thus, attempts to correlate Pan I frequency distribution with temperature at the time of sampling can be misleading for adult cod. One cannot exclude, however, that at the time of settling for juvenile cod, temperature may contribute to the segregation between the 2 stocks. A characteristic of Pan I allele frequency distribution of adult cod in northern Norway is the sharp inshore-offshore divergence (Sarvas \& Fevolden 2005a). A similar scenario was recently reported from Greenland waters (Pampoulie et al. 2011). Atlantic cod sampled within fjords of Greenland also had very high frequencies of the Pan $\mathrm{I}^{\mathrm{A}}$ allele, whereas cod taken well offshore had low frequencies of the same allele. Thus, there is reason to believe that specific features of fjord water contribute to the split between offshore and inshore populations, salinity being one likely factor. The salinity in shallow water in fjords is often low due to freshwater runoff. One could speculate that settling in shallow low-saline water is an adaptive strategy for coastal cod that evolved at a time glaciation isolated this population from the larger offshore populations in high-saline water. The ANC, with its deep-water settling strategy and migratory behavior, could signify a postglacial recolonization of the Barents Sea from historical offshore populations. The structure of many fish species, both freshwater and marine, is likely to be affected by the period previous to, during, and following the last glacial maximum (LGM), and ice-age refugia were recently suggested as contributing agents for the population structuring of Pacific cod Gadus macrocephalus (Canino et al. 2010). Isolated populations of Atlantic cod are reported from various northern meromictic lakes (Hardie et al. 2008), some of which have brackish or even freshwater upper layers. Pan I analyzed from 4 specimens in 1 of these, Lake Mogolnye, Kildin Island, on the Kola Peninsula, revealed 3 homozygotes for the Pan $\mathrm{I}^{\mathrm{A}}$ allele and 1 Pan $\mathrm{I}^{\mathrm{AB}}$ heterozygote. Likewise, 84 specimens of cod caught in the low-saline White Sea (Russia) in 2002 were close to fixed for the Pan $\mathrm{I}^{\mathrm{A}}$ allele (frequency of $98.2 \%$; our unpublished data). Thus, a closer look into low-salinity and Pan I affinities should be encouraged.

The 2 Pan I alleles in Atlantic cod appear to have diverged >2 Myr ago (Pogson \& Mesa 2004). Moreover, both the Pan $\mathrm{I}^{\mathrm{A}}$ and the Pan $\mathrm{I}^{\mathrm{B}}$ lineages show a long residency, in part endemic, in populations of cod both east and west in the North Atlantic (Pogson 2001, Bigg et al. 2008). There is reason to believe that the observed distinct differences in Pan I frequencies between $\mathrm{ANC}$ and $\mathrm{NCC}$ reflect a relatively 
recent diversifying adaptation, a structure that has appeared on an ecological rather than evolutionary timescale. The similar Pan I divergence for 0-group juveniles as for adults, and thus no indication of life history changes, lends no support to contemporary selection, but an adaptation most likely influenced by the LGM and physical oceanographic features following the gradual disappearance of ice.

Acknowledgements. We thank the crew on board RV 'Johan Ruud,' RV 'Helmer Hanssen,' and ships of the Marine Research Institute for assistance in sampling juvenile cod. We appreciate excellent laboratory assistance from T. Hanebrekke, A. Kettunen-Præbel, T. Sarvas Skarstein, and J. Volkers. We also thank C.A. Aas for allowing us to use his length-measured juvenile cod from Lyngsfjord 2005. Financial support was provided by the Norwegian Research Council plus internal funding from the University of Tromsø.

\section{LITERATURE CITED}

Árnason E (2004) Mitochondrial cytochrome $b$ DNA variation in the high-fecundity Atlantic cod: trans-Atlantic clines and shallow gene genealogy. Genetics 166: 1871-1885

Berg E, Albert OT (2003) Cod in fjords and coastal waters of North Norway: distribution and variation in length and maturity at age. ICES J Mar Sci 60:787-797

> Bergstad OA, Jørgensen T, Dragesund O (1987) Life history and ecology of the gadoid resources of the Barents Sea. Fish Res 5:119-161

Bigg GR, Cunningham CW, Ottersen G, Pogson GH, Wadley MR, Williamson P (2008) Ice age survival of Atlantic cod: agreement between palaeoecology models and genetics. Proc R Soc Lond B Biol Sci 275:163-172

- Canino MF, Spies IB, Cunningham CB, Hauser L, Grant S (2010) Multiple ice-age refugia in Pacific cod Gadus macrocephalus. Mol Ecol 19:4339-4351

> Carvalho GR, Hauser L (1998) Advances in the molecular analysis of fish populations. Ital J Zool 65:21-33

- Case RAJ, Hutchinson WF, Hauser L, Van Oosterhaut C, Carvalho GR (2005) Macro- and micro-geographic variation in pantophysin (PanI) allele frequencies in NE Atlantic cod Gadus morhua. Mar Ecol Prog Ser 301: $267-278$

Case RAJ, Hutchinson WF, Hauser L, Buehler V and others (2006) Association between growth and Pan $I^{*}$ genotype within Atlantic cod full-sibling families. Trans Am Fish Soc 135:241-250

Excoffier L, Lischer HEL (2010) Arlequin suite ver 3.5: a new series of programs to perform population genetics analyses under Linux and Windows. Mol Ecol Resour 10: 564-567

Fevolden SE, Pogson GH (1995) Differences in nuclear DNA RFLPs between the Norwegian coastal and the NorthEast Arctic population of Atlantic cod. In: Skjoldal HR, Hopkins C, Erikstad KE, Leinaas HP (eds) Ecology of fjords and coastal waters. Elsevier Science B.V., Amsterdam, p 403-415

Fevolden SE, Pogson GH (1997) Genetic divergence at the synaptophysin (Syp I) locus among Norwegian coastal and north-east Arctic populations of Atlantic cod. J Fish Biol 51:895-908

Foll M, Gaggiotti O (2008) A genome-scan method to identify selected loci appropriate for both dominant and codominant markers: a Bayesian perspective. Genetics 180:977-993

Godø OR (1986) Dispersion and mingling of cod from various nursery and feeding areas along the Norwegian coast and in the Barents Sea. In: Alton M (ed) Workshop on comparative biology, assessment and management of gadoids from the North Pacific and Atlantic Oceans. Northwest and Alaska Fisheries Center, Seattle, WA, p 663-672

Goudet J (2001) FSTAT, a program to estimate and test gene diversities and fixation indices (version 2.9.3). Available at www2.unil.ch/popgen/softwares/fstat.htm

> Grabowski TB, Thorsteinsson V, McAdam BJ, Marteinsdóttir G (2011) Evidence of segregated spawning in a single marine fish stock: sympatric divergence of ecotypes in Icelandic cod? PLoS ONE 6:e17528

Haass NK, Kartenbeck J, Leube RE (1996) Pantophysin is a ubiquitously expressed synaptophysin homologue and defines constitutive transport vesicles. J Cell Biol 134: 731-746

> Hardie DC, Renaud CB, Ponomarenko VP, Mukhina NV, Yaragina NA, Skjæraasen JE, Hutchings JA (2008) The isolation of Atlantic cod, Gadus morhua (Gadiformes), populations in northern meromictic lakes - a recurrent Arctic phenomenon. J Ichthyol 48:230-240

Helyar SJ, Hemmer-Hansen J, Bekkevold D, Taylor MI and others (2011) Application of SNPs for population genetics of nonmodel organisms: new opportunities and challenges. Mol Ecol Resour 11:123-136

Imsland AK, Jónsdóttir ODB (2003) Linking population genetics and growth properties of Atlantic cod. Rev Fish Biol Fish 13:1-26

Jakobsdóttir KB, Pardoe H, Magnússon A, Björnsson $H_{\text {, }}$ Pampoulie C, Ruzzante DE, Marteinsdóttir G (2011) Historical changes in genotypic frequencies at the Pantophysin locus in Atlantic cod (Gadus morhua) in Icelandic waters: evidence of fisheries-induced selection? Evol Appl 4:562-573

> Jakobsen T (1987) Coastal cod in Northern Norway. Fish Res $5: 223-234$

> Jónsdóttir ODB, Imsland AK, Danielsdóttir AK, Marteinsdóttir G (2002) Genetic heterogeneity and growth properties of different genotypes of Atlantic cod (Gadus morhua Lm) at two spawning sites off south Iceland. Fish Res 55: $37-47$

Jónsdóttir IG, Marteinsdóttir G, Pampoulie C (2008) Relation of growth and condition with the Pan I locus in Atlantic cod (Gadus morhua L.). Mar Biol 154:867-874

> Karlsson S, Mork J (2003) Selection-induced variation at the pantophysin locus (Pan I) in a Norwegian fjord population of cod (Gadus morhua L.). Mol Ecol 12:3265-3274

> Kirk H, Freeland JR (2011) Applications and implications of neutral versus non-neutral markers in molecular ecology. Int J Mol Sci 12:3966-3988

Løken S, Pedersen T, Berg E (1994) Vertebrae numbers as an indicator for the recruitment mechanism of coastal cod of northern Norway. ICES Mar Sci Symp 198: $510-519$

> Moen T, Hayes B, Nilsen F, Delghandi M and others (2008) Identification and characterisation of novel SNP markers in Atlantic cod: evidence for directional selection. BMC 
Genet 9:18

Mork J, Ryman N, Ståhl G, Utter F, Sundnes G (1985) Genetic variation in Atlantic cod (Gadus morhua) throughout its range. Can J Fish Aquat Sci 42:1580-1587

$>$ Nei M, Tajima F, Tateno Y (1983) Accuracy of estimated phylogenetic trees from molecular data. J Mol Evol 19: 153-170

> Nielsen EE, Hansen MM, Meldrup D (2006) Evidence of microsatellite hitch-hiking selection in Atlantic cod (Gadus morhua L.): implications for inferring population structure in nonmodel organisms. Mol Ecol 15: 3219-3229

> Nielsen EE, Hemmer-Hansen J, Larsen PF, Bekkevold D (2009a) Population genomics of marine fishes: identifying adaptive variation in space and time. Mol Ecol 18: 3128-3150

> Nielsen EE, Hemmer-Hansen J, Poulsen NA, Loeschcke V and others (2009b) Genomic signatures of local directional selection in a high gene flow marine organism; the Atlantic cod (Gadus morhua). BMC Evol Biol 9:276

Nordeide JT (1998) Coastal cod and northeast Arctic codDo they mingle at the spawning grounds in Lofoten? Sarsia 83:373-379

> Nordeide JT, Folstad I (2000) Is cod lekking or a promiscuous group spawner? Fish Fish 1:90-93

> Nordeide JT, Johansen SD, Jørgensen TE, Karlsen BO, Moum T (2011) Population connectivity among migratory and stationary cod Gadus morhua in the Northeast Atlantic - A review of 80 years of study. Mar Ecol Prog Ser 435:269-283

> Otterå H, Agmalt AL, Jørstad KE (2006) Differences in spawning time of captive Atlantic cod from four regions of Norway kept under identical conditions. ICES J Mar Sci 63:216-223

Otterlei E, Nyhammer G, Folkword A, Stefansson S (1999) Temperature- and size-dependent growth of larval and early juvenile Atlantic cod (Gadus morhua): a comparative study of Norwegian coastal cod and northeast Arctic cod. Can J Fish Aquat Sci 56:2099-2111

Pampoulie C, Jakobsdóttir KB, Marteinsdóttir G, Thorsteinsson V (2008) Are vertical behaviour patterns related to the pantophysin locus in the Atlantic cod (Gadus morhua L.)? Behav Genet 38:76-81

Pampoulie C, Daníelsdottír AK, Storr-Paulsen M, Hovgård H, Hjörleifsson E, Steinarsson BÆ (2011) Neutral and nonneutral genetic markers revealed the presence of inshore and offshore stocks components of Atlantic cod in Greenland waters. Trans Am Fish Soc 140:307-319

Pedersen OP, Zhou M, Tande KS, Edvardsen A (2005) Eddy formation on the coast of North Norway - evidenced by synoptic sampling. ICES J Mar Sci 62:615-628

Piry S, Alapetite A, Cornuet JM, Paetkau D, Baudouin L, Estoup A (2004) GeneClass2: a software for genetic assignment and first-generation migrant detection. J Hered 95:536-539

$>$ Pogson GH (2001) Nucleotide polymorphism and natural selection at the pantophysin (Pan I) locus in the Atlantic cod, Gadus morhua (L.). Genetics 157:317-330

> Pogson GH, Fevolden SE (2003) Natural selection and the genetic differentiation of coastal and Arctic populations of the Atlantic cod in northern Norway: a test involving nucleotide sequence variation at the pantophysin (Pan I) locus. Mol Ecol 12:63-74

Pogson GH, Mesa KA (2004) Positive Darwinian selection at the pantophysin (Pan I) locus in marine gadid fishes. Mol Biol Evol 21:65-75

Pogson GH, Mesa KH, Boutilier RG (1995) Genetic population structure and gene flow in the Atlantic cod Gadus morhua: a comparison of allozyme and nuclear RFLP loci. Genetics 139:375-385

> Poulsen NA, Hemmer-Hansen J, Loeschcke V, Carvalho GR, Nielsen EE (2011) Microgeographical population structure and adaptation in Atlantic cod Gadus morhua: spatio-temporal insights from gene-associated DNA markers. Mar Ecol Prog Ser 436:231-243

> Robichaud D, Rose GA (2004) Migratory behaviour and range in Atlantic cod: inference from a century of tagging. Fish Fish 5:185-214

> Rousset F (2008) Genepop 007: a complete re-implementation of the Genepop software for Windows and Linux. Mol Ecol Resour 8:103-106

> Salmenkova EA (2011) New view on the population genetic structure of marine fish. Russ J Genet 47:1279-1287

> Sarvas TH, Fevolden SE (2005a) Pantophysin (Pan I) locus divergence between inshore vs offshore and northern vs southern populations of Atlantic cod in the NE Atlantic. J Fish Biol 67:444-469

Sarvas TH, Fevolden SE (2005b) The scnDNA locus Pan I reveals concurrent presence of different populations of Atlantic cod (Gadus morhua L.) within a single fjord. Fish Res 76:307-316

> Skarstein TH, Westgaard JI, Fevolden SE (2007) Comparing microsatellite variation of north-east Atlantic cod (Gadus morhua L.) to genetic structuring as revealed by the pantophysin (Pan I) locus. J Fish Biol 70:271-290

Skjæraasen JE, Meager JJ, Karlsen Ø, Hutchings JA, Fernø A (2011) Extreme spawning-site fidelity in Atlantic cod. ICES J Mar Sci 68:1472-1477

Skreslet S, Danes GJ (1978) Seaward transport of eggs of coastal cod (Gadus morhua) from spawning grounds in Ullsfjord, north Norway. Astarte 11:11-20

> Stenvik J, Wesmajervi MS, Damsgård B, Delghandi M (2006) Genotyping of pantophysin (Pan I) of Atlantic cod (Gadus morhua L.) by allele-specific PCR. Mol Ecol Notes 6:272-275

Trippel EA, Kjesbu OS, Solemdal P (1997) Effects of adult age and size structure on reproductive output in marine fishes. In: Chambers RC, Trippel EA (eds) Early life history and recruitment in fish populations. Chapman \& Hall, London, p 31-62

Van Oosterhout C, Hutchinson WF, Wills DPM, Shipley P (2004) Micro-checker: software for identifying and correcting genotyping errors in microsatellite data. Mol Ecol Notes 4:535-538

> Vikebø F, Sundby S, Adlandsvik B, Fiksen $\varnothing$ (2005) The combined effect of transport and temperature distribution and growth of larvae and pelagic juveniles of ArctoNorwegian cod. ICES J Mar Sci 62:1375-1386

> Waples RS, Gagiotti O (2006) What is a population? An empirical evaluation of some genetic methods for identifying the number of gene pools and their degree of connectivity. Mol Ecol 15:1419-1439

Weir BS, Cockerham C (1984) Estimating F-statistics for the analysis of population structure. Evolution 38:1358-1370

> Westgaard JI, Fevolden SE (2007) Atlantic cod (Gadus morhua L.) in inner and outer coastal zones of northern Norway display divergent genetic signature at nonneutral loci. Fish Res 85:306-315 